\title{
Ciclos de mejora en aula (CIMA) virtuales en Anatomía Patológica: adaptándonos al cambio para ganar en calidad de aprendizaje
}

\section{Virtual Classroom-based improvement cycles (CIMA) in Pathology: adapting to change to gain in learning quality}

EnRIQUe de Álava CASAdo

ORCID: https://orcid.org/0000-0001-8400-046X Universidad de Sevilla

Departamento de Citología e Histología Normal y Patológica y UGC Anatomía Patológica, Hospital Universitario Virgen del Rocío-IBiS / AGS Osuna ealava-ibis@us.es

DOI: http://dx.doi.org/10.12795/9788447231003.075 Pp.: 1599-1622 


\section{Contexto de la asignatura}

La asignatura donde estoy realizando los ciclos de mejora es "Anatomía Patológica", correspondiente al primer semestre del tercer curso del grado de Medicina. Consta de 9 créditos repartidos, cada semana, en cuatro clases teóricas más 3 horas de prácticas o seminarios de una hora. Es una asignatura troncal y de formación básica (obligatoria), que se imparte en el primer cuatrimestre del curso. Los alumnos ya han cursado Histología y Anatomía. Consta de 50 temas, agrupados en 8 secciones temáticas. En el curso 2020-2021, imparto docencia sólo a un grupo de 90 personas, y en este grupo imparto tanto la docencia teórica como las prácticas y los seminarios. Esto me ofrece una oportunidad única para mejorar el aprendizaje de los alumnos integrando la formación teórica con la práctica, centrándola más en los contenidos procedimentales clínicos.

Las principales conclusiones que se desprenden del trabajo del curso pasado son:

\section{Avances conseguidos}

- Hemos sido capaces de centrar la docencia en casos (problemas clínicos reales) y de hecho hemos empezado cada CIMA con casos prácticos. Para no crear inseguridad en los estudiantes, hemos incluido 'clases teóricas' inmediatamente después, para consolidar los conocimientos aprendidos. Así, hemos dedicado a la misma área temática dos formatos diferentes de docencia (clase teórica y seminario, por ejemplo) en dos días correlativos, repartiendo e integrando los contenidos entre los dos tipos de formatos presenciales de docencia. El resultado es que la diferencia entre clases teóricas y prácticas/seminarios se ha difuminado notablemente.

- El nivel de participación de los estudiantes ha sido notablemente mejor, lo que se ha favorecido por haber Ciclos de Mejora en el Aula (2020). Experiencias de Innovación Docente de la US
Esta obra se distribuye con la licencia Creative Commons 
asignado (ver siguiente apartado) un 25\% de la calificación a la cantidad y calidad de la participación en los cuestionarios. Si en el curso pasado la participación era de 5-8 alumnos por cuestionario, ésta no ha bajado de los 80 en el curso actual.

- De manera complementario al punto anterior, hemos introducido aspectos de clase invertida en nuestra docencia y hemos sido capaces de modular los contenidos de algunas clases teóricas gracias a los cuestionarios que, durante los CIMA 1 y 2 , hemos abierto a la participación de los estudiantes.

- Hemos sido capaces de extender el modelo de CIMAs a la segunda mitad del te-mario, mucho más clínico.

- Por primera vez, incluimos un 25\% de la calificación final a actividades de evaluación continua (basada en los cuestionarios previos/posteriores a cada CIMA)

\section{Retos y aspectos a mejorar}

- El reto principal para este curso 2020-2021 es adaptarnos a un escenario fundamentalmente virtual (en la Facultad de Medicina US), e intentar que el aprendizaje de los alumnos no sólo no se resienta, sino que sea reforzado con la metodología aplicada.

- Progresar en mi modelo docente universitario desde un modelo de resolución de problemas cerrados a un verdadero modelo constructivista e investigativo, superando los obstáculos epistemológicos, lo que supone un reto porque en mi disciplina los contenidos procedimentales (diagnóstico anatomopatológico) están bastante estandarizados y el alumno los desconoce en buena parte antes de formular sus hipótesis (de Alba et al., 2020).

- Puesto que todas las actividades van a ser virtuales, he creado un grupo de Microsoft Teams (herramienta corporativa de la US, ver enlace a la carpeta) que funcione como un FORO de comunicación, intercambio de ideas Ciclos de Mejora en el Aula (2020). Experiencias de Innovación Docente de la US
Esta obra se distribuye con la licencia Creative Commons 
y materiales, con la finalidad de estar atentos a las concepciones de los alumnos y enviar de manera informal elementos de contraste (vídeos, artículos científicos, etc.) para los que la herramienta "Foro" de BlackBoard Collaborate es un poco obsoleta.

- Existen algunas clases cuyos materiales aún son demasiado largos y complejos, y necesitarían ser jerarquizados y resumidos de manera radical para mejorar el aprendizaje del alumnado.

- Convendría escribir pies de figura en algunas figuras con contenidos complejos.

- Las escaleras de aprendizaje revelan que hay algunos contenidos (p.ej. biomarcadores en el carcinoma de pulmón, concepto de metástasis) en los que se debe mejorar el aprendizaje, para lo que deberemos pensar nuevas estrategias docentes.

\section{Diseño previo}

\section{Resumen de la actuación}

Se han diseñado 14 CIMA, que, por brevedad, nombraremos con las letras $A-M$ (pero tienen nombres atractivos para los estudiantes), y en los que se sincronizan e integran las clases teóricas con los seminarios y prácticas relacionados temáticamente.

1. Los CIMAs A-E corresponden a la primera mitad de la asignatura, donde ponemos el foco en aprender los mecanismos básicos de la enfermedad (p.ej. la infección, la inflamación, la neoplasia, etc.) que son transversales o subyacen a cada enfermedad.

2. Los CIMAs F-N corresponden a la segunda mitad de la asignatura, en la que el objetivo es tener una primera aproximación a las diferentes enfermedades de cada órgano o sistema, una vez comprendidos los mecanismos básicos de la enfermedad.

Ciclos de Mejora en el Aula (2020). Experiencias de Innovación Docente de la US Esta obra se distribuye con la licencia Creative Commons 
3. He intercalado clases de repaso (repaso/repeMIR), que se dedicarán a integración de conocimientos de cada CIMA con los de CIMAs previos y donde se debatirán preguntas de Anatomía Patológica de exámenes MIR de años previos.

4. En todos los CIMAs se hace mucho hincapié en contenidos procedimentales, que aparecen explicitados en forma de seminarios y prácticas, pero que en realidad están casi igualmente presentes en las 'clases teóricas'.

5. He apoyado en todos los CIMAs las clases teóricas en clases prácticas o seminarios previos con casos clínicos sencillos y adaptados a los estudiantes de tercer curso de Medicina. Se adjunta una tabla con el resumen de la actuación.

Tabla 1. Características de cada CIMA propuesto

\begin{tabular}{|c|c|c|c|c|c|}
\hline CIMA ne & Nombre del CIMA & $\begin{array}{c}\text { temas de teoŕa integrados } \\
\text { en el cIMA }\end{array}$ & $\begin{array}{c}\text { seminarios integrados en } \\
\text { el CIMA }\end{array}$ & $\begin{array}{c}\text { prácticas integradas en el } \\
\text { CMMA }\end{array}$ & Total de horas \\
\hline A & $\begin{array}{l}\text { ¿Cómo responde la } \\
\text { célula? }\end{array}$ & no 1-6 & noo & n⿻0 & 8 \\
\hline B & $\begin{array}{l}\text { La circulación se } \\
\text { altera }\end{array}$ & no 7-9 & ำ1 + repaso ำ1 & no1 (primera parte) & 6 \\
\hline c & $\begin{array}{c}\text { El organismo } \\
\text { reacciona }\end{array}$ & ก10-16 & $n=2$ y 3 & no1 (segunda parte) & 10 \\
\hline D & $\begin{array}{l}\text { La amenaza de las } \\
\text { neoplasias }\end{array}$ & no 17-21 & no4 & no2 & 7 \\
\hline E & $\begin{array}{l}\text { Genes y medio } \\
\text { ambiente }\end{array}$ & no22-24 & repaso no2 & no & 4 \\
\hline $\mathbf{F}$ & $\begin{array}{l}\text { Enfermedades } \\
\text { circulatorias y } \\
\text { respiratorias }\end{array}$ & $n=25-29$ & no5 & no & 7 \\
\hline G & $\begin{array}{l}\text { Enfermedades } \\
\text { digestivas y del } \\
\text { hígado }\end{array}$ & n031-36 & no6 + repaso no3 & no3 & 9 \\
\hline H & $\begin{array}{l}\text { Enfermedades del } \\
\text { aparato urinario }\end{array}$ & no37-38 & no7 & no & 3 \\
\hline 1 & $\begin{array}{l}\text { Enfermedades del } \\
\text { sistema linfoide }\end{array}$ & no39-40 & no & no & 2 \\
\hline J & $\begin{array}{c}\text { Enfermedades del } \\
\text { aparato genital y la } \\
\text { mama }\end{array}$ & nะ41-45 & no8 & nะ4 & 6 \\
\hline $\mathrm{k}$ & $\begin{array}{c}\text { Enfermedades } \\
\text { endocrinas }\end{array}$ & nะ45 & no & no5 & 2 \\
\hline $\mathbf{L}$ & $\begin{array}{l}\text { Enfermedades del } \\
\text { sistema } \\
\text { musculoesquelético }\end{array}$ & กำ6-47 & no & no & 2 \\
\hline M & $\begin{array}{c}\text { Patología del sistema } \\
\text { nervioso }\end{array}$ & ก48 & no9 & no & 2 \\
\hline
\end{tabular}

Ciclos de Mejora en el Aula (2020). Experiencias de Innovación Docente de la US Esta obra se distribuye con la licencia Creative Commons Reconocimiento-NoComercial-SinObraDerivada Internacional (CC BY-NC-ND 4.0.) 


\section{Principios didácticos argumentados comunes a los 14 ciclos}

Respecto a los contenidos he hecho una reflexión sobre los más estructuradores (p.ej. concepto de neoplasia, cómo diagnosticar una neoplasia), los más conceptuales y los procedimentales. Además, se han incluido habilidades procedimentales como la de describir lesiones o la de hablar en público. También se han incluido valores, como el de la prevención o la investigación.

Respecto al modelo metodológico, éste se ha basado en el trabajo de casos clínicos de forma individual o grupal de manera previa o durante la clase, de forma que ayude a los estudiantes a ser capaces de relacionar los conceptos teóricos con la realidad clínica. Parece importante tener una interacción muy estrecha con los alumnos durante la preparación de las clases, invitándoles a aprovechar este momento para exponerse a la materia. Para el profesor, este tiempo es privilegiado para conocer de manera específica (mediante cuestionarios especialmente diseñados a tal efecto, y más directamente, mediante el chat de MsTeams) qué es lo que les cuesta más comprender a los alumnos y para introducir cambios que favorezcan la mejora del aprendizaje. Estos principios se han basado en las recomendaciones de Bain (2007) y Finkel (2005) sobre el aprendizaje autónomo de los alumnos. También se han incluido algunos elementos de aprendizaje inverso o inductivo "flipped learning", según las recomendaciones de Prieto (2018).

\section{Modelo metodológico argumentado común para los CIMA}

En el modelo metodológico seguido en los CIMA, comenzamos el estudio de cada bloque temático con el debate de casos clínicos (en formato seminario o práctica), y se continúa en los siguientes días con las explicaciones 
teóricas que ayudan a la resolución de estos, (en formato clase teórica) de la siguiente forma:

- Como trabajo previo a la sesión, el profesor sube a EV los materiales propuestos en relación con el caso clínico (CP) que va a servir de hilo conductor para comprender los contenidos teóricos

- Además, de manera previa a la clase el profesor envía cuestionarios de comprobación de estudio (módulo "Tarea" de BlackBoard Collaborate) que sirven para verificar el trabajo del alumno antes de clase, para hacer llegar feedback al profesor acerca de las dudas más urgentes y de las preguntas más interesantes, lo que permite al profesor replantear los contenidos de la clase de manera previa a su impartición, y para ayudar a construir las escaleras de aprendizaje.

- Se inicia la práctica o el seminario con la exposición del caso clínico, y con un trabajo de debate de este en forma de preguntas intercaladas con discusión por grupos de 6 personas y explicaciones aclaratorias. La práctica o seminario termina con cuestionarios de comprobación de aprendizaje mediante sistemas de gamificación tipo Kahoot dirigidos a centrar a los alumnos sobre algún tema clave de la sesión y a saber qué conceptos previos han conocido; las respuestas se envían de manera anónima y se programa el aplicativo para que no salga la respuesta correcta, de tal manera que se mantiene el 'suspense' y con ello la atención.

- Durante el tiempo no presencial que sigue, los alumnos pueden dirigir dudas y preguntas al profesor mediante un cuestionario específico, y éste está a tiempo de reformular la clase en lo que sea necesario.

- En la siguiente clase teórica, se comienza dando feedback a los alumnos acerca de las dudas más relevantes o urgentes. Posteriormente hay varias (2-3) "píldoras" de explica-ción teórica que en total suman 30 minutos $(T)$. A continuación, se repite el televoto mediante sistemas de gamificación tipo Kahoot (EV); se trata de las mismas preguntas que al principio de la clase; en este caso el sistema pregunta su nombre a cada alumno y le 
proporciona la respuesta correcta (2 minutos). El profesor puede así comprobar in situ si ha habido o no aprendizaje de los cometidos deseados durante la sesión. La sesión acaba con un feedback final por parte del profesor.

- En el tiempo que sigue a la clase, los alumnos vuelven a tener acceso al mismo cuestionario de comprobación de estudio en módulo "Actividad" de BlackBoard Collaborate, lo que permite al profesor evaluar el CIMA y construir las escaleras de aprendizaje. Todo ello queda recogido en la Figura 1.

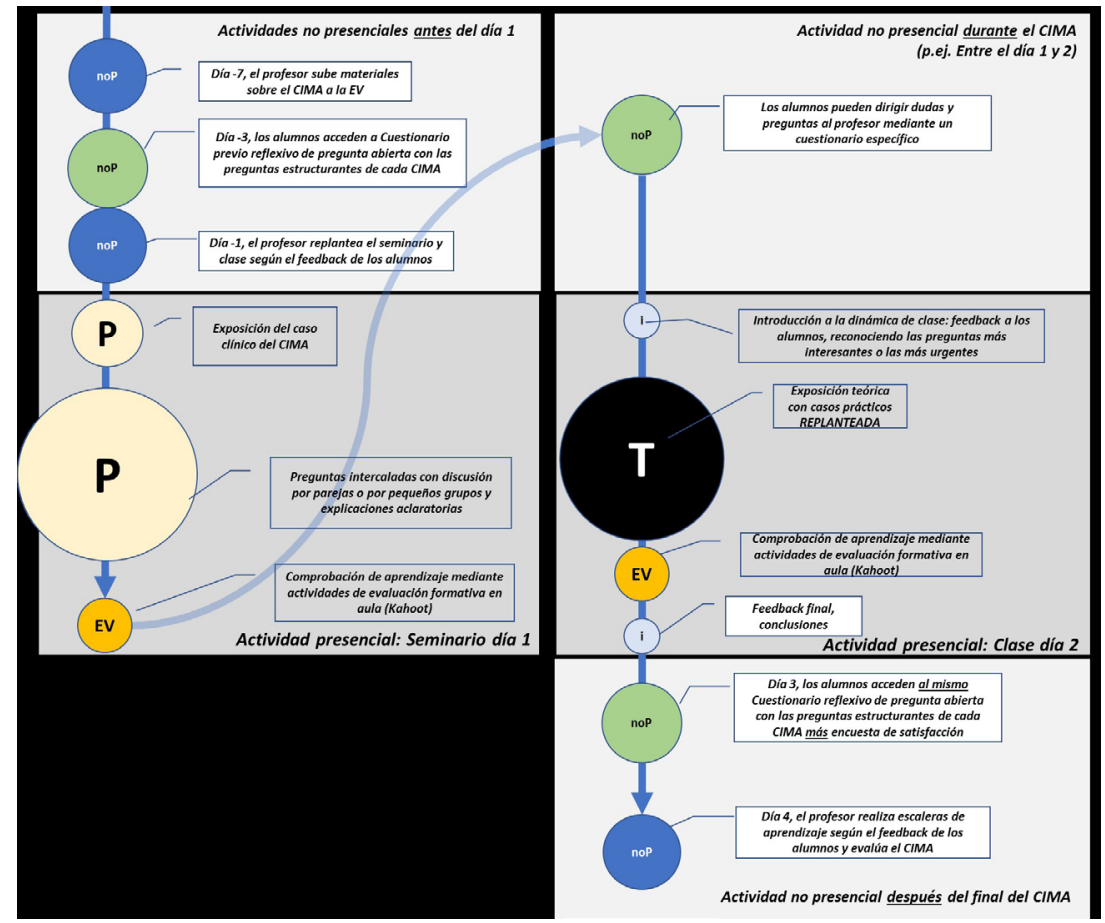

Figura 1. Modelo metodológico común a los 14 CIMA

Leyenda: P: Contenido práctico en relación con el caso clínico. noP: Actividad personal del alumno del profesor. I: introducción a la dinámica de clase. EV: Evaluación mediante televoto. T: Exposición teórica por parte del profesor de los contenidos teóricos en los que se apoya la resolución de las preguntas planteadas en el caso clínico. Ciclos de Mejora en el Aula (2020). Experiencias de Innovación Docente de la US 
A continuación, detallo los aspectos específicos de cada ciclo de mejora:

\section{CIMAs A-E}

\section{Mapa de contenidos y problemas o preguntas clave}

En estos cinco primeros CIMAs se imparten los temas referentes a las bases celulares y moleculares de la enfermedad relacionadas con los cambios en las propias células, la circulación de la sangre, la inflamación, las infecciones, los genes heredados y las neoplasias. Se llevan a cabo en sesiones de 55 minutos. Son temas importantes, aunque relativamente fáciles, y hacen por ello que la introducción del nuevo modelo metodológico por primera vez en el Grado no desconcierte, sino que estimule a los estudiantes.

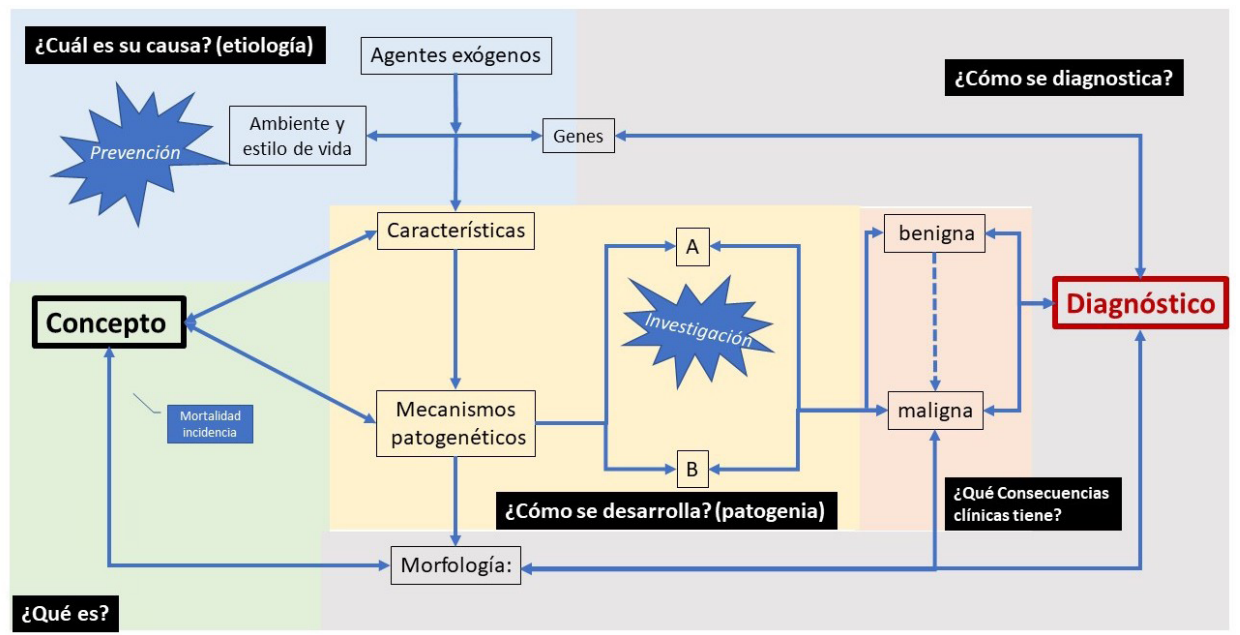

Figura 2. Mapa de contenidos de los CIMAs A-E. El gráfico representa las cinco preguntas clave comunes de los CIMAs relacionados con las bases celulares y moleculares de la enfermedad). Conceptos fundamentales: negrita. Contenidos conceptuales: Negro; contenidos procedimentales: rojo. Estrellas: valores. Flechas: relaciones entre contenidos. Flecha discontinua: relación probable. Ciclos de Mejora en el Aula (2020). Experiencias de Innovación Docente de la US 
A continuación, se detallan las preguntas clave:

1. ¿Qué es?

2. ¿Cuál es su causa? (etiología)?

3. ¿Cómo se desarrolla (patogenia)?

4. ¿Qué consecuencias clínicas tienen estas alteraciones?

5. ¿Cómo se diagnostican estas alteraciones?

\section{Secuencia de actividades antes de aplicar el ciclo de mejora}

La exposición de toda la secuencia de actividades de los CIMAs A-E excede del espacio permitido para este documento. Exponemos a continuación el Esquema y temporalización de actividades del CIMA B ("la circulación se altera") para el grupo 3으 de Medicina. Nótense las ligeras diferencias, graduales, en la manera de preparación y exposición del trabajo realizado por los alumnos.

Tabla 2. Secuencia de actividades del CIMA B

\begin{tabular}{|c|c|c|c|}
\hline Día & Actividad & $\begin{array}{l}\text { Tiempo } \\
\text { (minutos) }\end{array}$ & Clave \\
\hline \multirow{4}{*}{$\begin{array}{l}\text { Día 0, } \\
15 \text { de } \\
\text { octubre }\end{array}$} & $\begin{array}{l}\text { Clase final del CIMA previo (A), tema } \\
6\end{array}$ & $35^{\prime}$ & \\
\hline & $\begin{array}{l}\text { Introducción a la dinámica del } \\
\text { CIMA B: caso clínico del seminario } \\
1 \text { (Hiperemia, edema, hemorragia } \\
\text { y shock), entrega de material (en } \\
\text { Enseñanza Virtual) y explicación }\end{array}$ & $15^{\prime}$ & $P$ \\
\hline & Final de la clase & - & \\
\hline & $\begin{array}{l}\text { Trabajo INDIVIDUAL fuera de clase: } \\
\text { cuestionarios }\end{array}$ & $\begin{array}{l}70^{\prime} \text { (máximo } \\
\text { recomendable) }\end{array}$ & $A G$ \\
\hline
\end{tabular}

Ciclos de Mejora en el Aula (2020). Experiencias de Innovación Docente de la US Esta obra se distribuye con la licencia Creative Commons 


\begin{tabular}{|c|c|c|c|}
\hline \multirow{6}{*}{$\begin{array}{l}\text { Día 1o, } \\
\text { viernes } \\
16 \text { de } \\
\text { octubre }\end{array}$} & $\begin{array}{l}\text { Introducción a la dinámica de la } \\
\text { clase. }\end{array}$ & $5^{\prime}$ & i \\
\hline & $\begin{array}{l}\text { Exposición del caso clínico del } \\
\text { seminario nô. }\end{array}$ & $20^{\prime}$ & P \\
\hline & Debate con los alumnos. & $20^{\prime}$ & $\mathrm{T}$ \\
\hline & Mini evaluación televoto & $5^{\prime}$ & EV \\
\hline & Final de la clase & - & - \\
\hline & Trabajo INDIVIDUAL fuera de clase: & $\begin{array}{l}10^{\prime} \text { (máximo } \\
\text { recomendable) }\end{array}$ & $A G$ \\
\hline \multirow{6}{*}{$\begin{array}{l}\text { Día 2o, } \\
\text { lunes } \\
19 \text { de } \\
\text { octubre }\end{array}$} & $\begin{array}{l}\text { Introducción a la dinámica de la } \\
\text { clase. Feedback a los alumnos }\end{array}$ & $10^{\prime}$ & i \\
\hline & $\begin{array}{l}\text { Exposición teórica del profesor } \\
\text { acerca del tema } \mathbf{7} \text { para fijar } \\
\text { conceptos y mostrar imágenes } \\
\text { significativas del caso. }\end{array}$ & $30^{\prime}$ & $\mathrm{T}$ \\
\hline & Mini evaluación televoto & $5^{\prime}$ & EV \\
\hline & Feedback a los alumnos & $5^{\prime}$ & $P$ \\
\hline & Final de la clase & - & - \\
\hline & Trabajo INDIVIDUAL fuera de clase: & $\begin{array}{l}10^{\prime} \text { (máximo } \\
\text { recomendable) }\end{array}$ & \\
\hline \multirow{4}{*}{$\begin{array}{l}\text { Día 3o, } \\
\text { martes } \\
20 \text { de } \\
\text { octubre }\end{array}$} & $\begin{array}{l}\text { Introducción a la dinámica de la } \\
\text { clase. Feedback a los alumnos }\end{array}$ & $10^{\prime}$ & i \\
\hline & $\begin{array}{l}\text { Exposición teórica del profesor } \\
\text { acerca del tema } \mathbf{8} \text { para fijar } \\
\text { conceptos y mostrar imágenes } \\
\text { significativas del caso. }\end{array}$ & $30^{\prime}$ & $\mathrm{T}$ \\
\hline & Mini evaluación televoto & $5^{\prime}$ & EV \\
\hline & Feedback a los alumnos & $5^{\prime}$ & $P$ \\
\hline
\end{tabular}

Ciclos de Mejora en el Aula (2020). Experiencias de Innovación Docente de la US Esta obra se distribuye con la licencia Creative Commons Reconocimiento-NoComercial-SinObraDerivada Internacional (CC BY-NC-ND 4.0.) 


\begin{tabular}{|c|c|c|c|}
\hline \multirow{4}{*}{$\begin{array}{l}\text { Día 4o, } \\
\text { miércoles } \\
21 \text { de } \\
\text { octubre }\end{array}$} & $\begin{array}{l}\text { Introducción a la dinámica de la } \\
\text { clase. Feedback a los alumnos }\end{array}$ & $10^{\prime}$ & $\mathrm{i}$ \\
\hline & $\begin{array}{l}\text { Exposición teórica del profesor } \\
\text { acerca del tema } 9 \text { para fijar } \\
\text { conceptos y mostrar imágenes } \\
\text { significativas del caso. }\end{array}$ & $30^{\prime}$ & $\mathrm{T}$ \\
\hline & Mini evaluación televoto & $5^{\prime}$ & EV \\
\hline & Feedback a los alumnos & $5^{\prime}$ & $P$ \\
\hline \multirow{5}{*}{$\begin{array}{l}\text { Día 5o, } \\
\text { jueves } \\
22 \text { de } \\
\text { octubre }\end{array}$} & $\begin{array}{l}\text { Introducción a la dinámica de la } \\
\text { clase. Feedback a los alumnos }\end{array}$ & $10^{\prime}$ & i \\
\hline & $\begin{array}{l}\text { Trabajo por grupos con algunas } \\
\text { preguntas tipo test sacadas de } \\
\text { exámenes MIR de los años 2016-2020 } \\
\text { (Kahoot) }\end{array}$ & $10^{\prime}$ & \\
\hline & Feedback sobre las respuestas & $10^{\prime}$ & $\mathrm{T}$ \\
\hline & $\begin{array}{l}\text { Mini-píldora teórica para aclarar } \\
\text { aspectos dudosos }\end{array}$ & $10^{\prime}$ & EV \\
\hline & $\begin{array}{l}\text { Feedback final e introducción del } \\
\text { día } 6\end{array}$ & $5^{\prime}$ & $P$ \\
\hline \multirow{5}{*}{$\begin{array}{l}\text { Día 6o, } \\
\text { viernes } \\
23 \text { de } \\
\text { octubre }\end{array}$} & $\begin{array}{l}\text { Introducción a la dinámica de la } \\
\text { práctica nô1. Feedback a los alumnos }\end{array}$ & $10^{\prime}$ & i \\
\hline & $\begin{array}{l}\text { Trabajo por grupos con imágenes } \\
\text { escaneadas de casos clínicos }\end{array}$ & $10^{\prime}$ & $\mathrm{T}$ \\
\hline & $\begin{array}{l}\text { Mini evaluación sobre las imágenes } \\
\text { (Kahoot televoto) }\end{array}$ & $5^{\prime}$ & EV \\
\hline & $\begin{array}{l}\text { Realización de la prueba de } \\
\text { evaluación continua del CIMA B (10 } \\
\text { preguntas al azar Módulo exámenes } \\
\text { de BlackBoard Collaborate) }\end{array}$ & $10^{\prime}$ & $P$ \\
\hline & $\begin{array}{l}\text { Feedback a los estudiantes sobre las } \\
\text { respuestas correctas }\end{array}$ & $10^{\prime}$ & EV \\
\hline
\end{tabular}

Ciclos de Mejora en el Aula (2020). Experiencias de Innovación Docente de la US Esta obra se distribuye con la licencia Creative Commons Reconocimiento-NoComercial-SinObraDerivada Internacional (CC BY-NC-ND 4.0.) 


\title{
Caso clínico del tema 9
}

\author{
¿Qué tenía que haber evitado Roberto?
}

Roberto era conductor de autobús desde hace muchos años. Cuando lo conoci tenía 54 años. Fue hace tres meses, cuando vino a la consulta de Atención Primaria acompañado por su pareja. Me comentaron que el dia anterior, tras una comida copiosa, a la salida del restaurante, desarrolló un dolor por delante del pecho que se movia hacia el brazo izquierdo, pero que el dolor desapareció al tumbarse en el sofá de casa. En los primeros minutos de la entrevista me reconoce cuando se lo pregunto, que nunca ha hecho actividad física y que es adicto al tabaco. De hecho, tiene las yemas de los dedos y los dientes tiznados de nicotina y está obeso, pues mide $176 \mathrm{~cm}$ y pesa $98 \mathrm{~kg}$. Le tomo la tensión (155/105), y vi en la historia clínica que eso lleva pasando desde hace años. Le solicité un análisis de sangre, y comprobé que el resultado es muy elevado ( $240 \mathrm{mg} / \mathrm{dL}$ ).

Me llaman esta misma mañana desde el 112, y me comentan que Roberto ha tenido un episodio de dolor más severo del anterior, tras el que ha fallecido. La familia accede a que se pueda realizar la autopsia.

\section{Cuestiones:}

1. ¿Cuál es la causa más probable de la muerte?

2. Dibuja o encuentra imágenes en internet (no en enseñanza virtual) que describan la morfologia macroscópica y microscópica del corazón.

3. Haz una relación de órganos o tejidos afectados por la hipertensión arterial. ¿Qué lesiones puede originar en esos órganos y tejidos?

4. Haz una tabla que muestre la correlación entre la clínica de este paciente y los posibles hallazgos anatomopatológicos.

5. ¿Qué tenia que haber evitado Roberto? ¿Por qué?

Figura 3. Se muestra, como ejemplo, la ficha del caso clínico del seminario nô1, con el que se abre el CIMA B

Ciclos de Mejora en el Aula (2020). Experiencias de Innovación Docente de la US Esta obra se distribuye con la licencia Creative Commons 


\section{Evaluación}

Se realiza una evaluación del estudiante durante el proceso de aprendizaje mediante cuestionarios, cuyas respuestas se analizan según el modelo de escaleras de aprendizaje propuesto por FIDOP. Se incluye también una evaluación del estudiante tras el proceso de aprendizaje. Por último, existe un sistema de evaluación del docente y del diseño didáctico mediante una estructura de autoevaluación y de evaluación del diseño de los ciclos de mejora.

1. Se muestra a continuación el cuestionario que se dirige a los alumnos antes del CIMA en el siguiente enlace: https://forms.gle/FhnFbQfTTdcxjn66A e incluye espacio para que respondan a las 5 preguntas estructurantes enunciadas.

2. El cuestionario intermedio que se envía durante el CIMA se puede encontrar aquí: https://forms.gle/ EoUdvV2QRue6crCX8

Durante la ejecución de estos CIMAs he sustituido el cuestionario intermedio por el chat de MsTeams, con el que la comunicación es mucho más fluida y horizontal.

3. Y el cuestionario posterior al CIMA se encuentra en este enlace: https://forms.gle/nm8N3d42qVfuEnPt9 El cuestionario es similar al cuestionario previo, pero incluye, además, estas otras cinco preguntas acerca del aprendizaje:

- ¿Cuál te parece la idea más importante o interesante que has aprendido en este CIMA y justifica brevemente por qué?

- Haz una crítica constructiva de los materiales subidos a la Enseñanza Virtual; si se te ocurre alguna sugerencia concreta no dejes de hacerla.

- ¿Qué aspecto de los tratados en el CIMA te gustaría indagar o profundizar por tu cuenta?

Ciclos de Mejora en el Aula (2020). Experiencias de Innovación Docente de la US Esta obra se distribuye con la licencia Creative Commons 
- Si tras terminar el CIMA crees que has comprendido algo importante que al principio no comprendías, indica primero qué es eso que has comprendido, y después propón una pregunta de examen que pueda servir para comprobar si otros compañeros también la han comprendido.

- Valora tu satisfacción tras este CIMA entre el 0 (poco satisfecho/a) y el 10 (muy satisfecho/a)

Todos estos cuestionarios se responden fácilmente, dan mucha información al profesor. Durante la ejecución de los CIMA he conseguido integrarlos en la herramienta "Actividad" de BlackBoard Collaborate, lo que supone menos facilidad para la explotación de la información, pero, como notable ventaja, supone que su calificación se integra automáticamente en el centro de calificaciones, lo que, además, supone que el alumno acede a su calificación en el mismo momento en que el profesor la califica.

\section{CIMAs F-N}

\section{Mapa de contenidos y problemas o preguntas clave}

Estos 8 CIMAs se llevan a cabo en entre 2 y 7 sesiones de 55 minutos, combinando clases teóricas, prácticas y seminarios, como se establece en la Tabla no1. Estos CIMAs están situado en la parte final del programa. Esto ayuda a los alumnos (¡y al profe!) a no relajarse tras los dos primeros ciclos de mejora. Además, los contenidos cambian respecto a la primera parte del programa, pues ya no se trata tanto de comprender los mecanismos básicos de la enfermedad, sino que describimos ahora enfermedades concretas. Es posible que en el curso 2021-2022 alguno de estos CIMA pueda convertirse en CIMA integrados con Patología Médica y Quirúrgica de 4으 o 5o curso de Medicina.

Ciclos de Mejora en el Aula (2020). Experiencias de Innovación Docente de la US Esta obra se distribuye con la licencia Creative Commons 


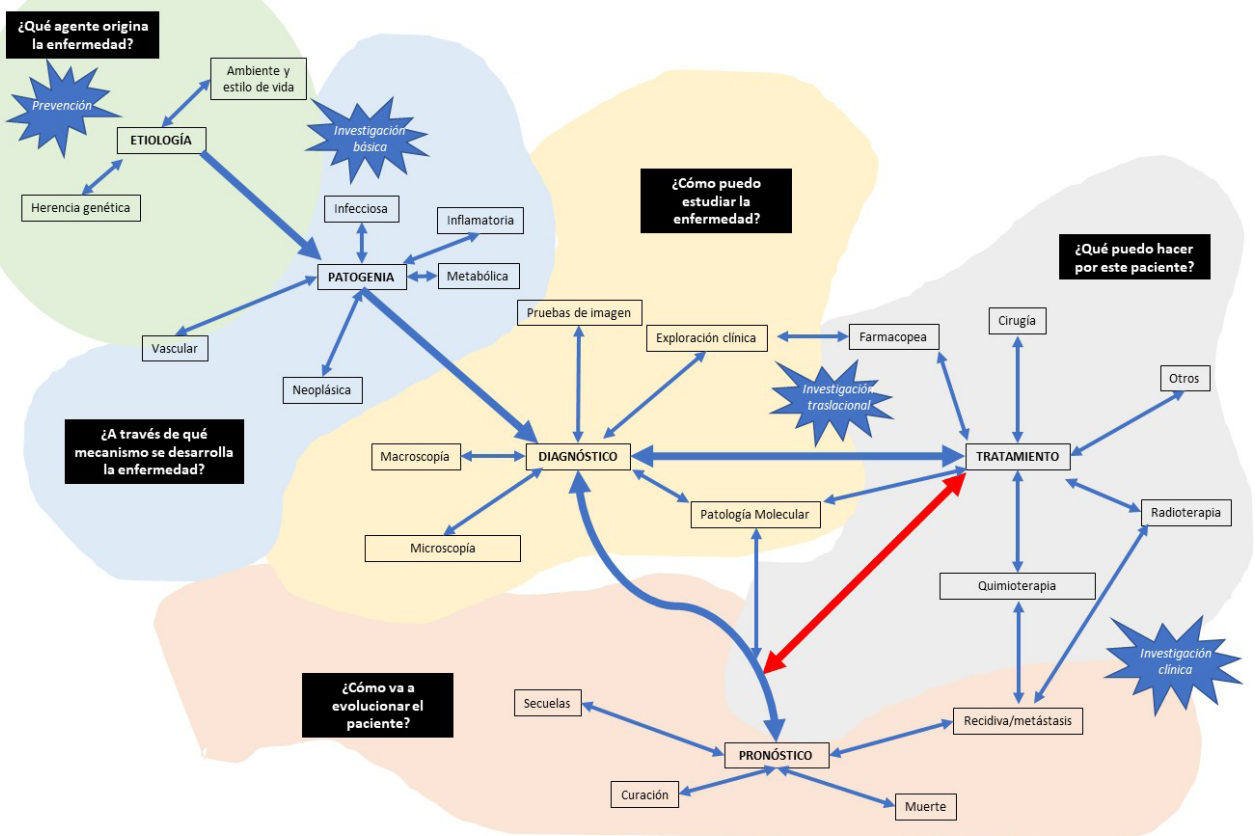

Figura 4. Mapa de contenidos común a los CIMA F-N.

Se observan las cinco preguntas estructurantes en cajas negras, centrando espacios de colores diferenciados donde se encuentran los contenidos y sus relaciones. Para un alumno de tercer curso de medicina todos los contenidos con cajas blancas son conceptuales, excepto los del área amarilla (diagnóstico), que son procedimentales. Algunos contenidos conceptuales se escriben con letras mayúsculas, dada su importancia. Se indican dos contenidos-valores con cajas de forma estrellada. Las flechas indican las relaciones entre los contenidos; su grosor y su color están en relación con su importancia.

A continuación, se detallan las preguntas clave genéricas, para cada CIMA 'la enfermedad' se sustituye por el área temática de cada CIMA, por ejemplo, en el CIMA F 'carcinoma de pulmón':

1. ¿Qué agente causa la enfermedad?

Ciclos de Mejora en el Aula (2020). Experiencias de Innovación Docente de la US Esta obra se distribuye con la licencia Creative Commons 
2. ¿A través de qué mecanismo se desarrolla la enfermedad?

3. ¿Cómo puedo estudiar la enfermedad?

4. ¿Cómo va a evolucionar el paciente?

5. ¿Qué puedo hacer por este paciente?

Secuencia de actividades de los CIMA F-N: Es en todo análoga a la de los CIMA A-E

Evaluación de los CIMA F-N: De manera análoga a los CIMA A-E, con cuestionarios similares y escaleras de aprendizaje.

\section{Aplicación del CIMA}

En el momento de enviar esta comunicación, se han terminado y evaluado los CIMA A-F, y están pendientes los CIMA G-N. Se transcriben los diarios de aula de los CIMA B y D.

\section{CIMA B}

Resumen del diario de clase:

El primer día (16 de octubre) empezamos el ciclo, tal y como habíamos quedado, con un seminario dedicado a una historia clínica de arteriosclerosis. Es la primera vez que ven un caso clínico en una clase en su vida, y les pongo una historia sencilla. Confieso que estoy un poco nervioso para ver cómo van a reaccionar, pero los veo muy interesados; les muestro las conexiones entre los contenidos procedimentales del seminario y los más conceptuales de las clases que vamos a ir teniendo en los próximos días. Me alegro de haber comenzado el CIMA con un caso clínico. Les doy feedback sobre el cuestionario previo al

Ciclos de Mejora en el Aula (2020). Experiencias de Innovación Docente de la US Esta obra se distribuye con la licencia Creative Commons 
CIMA, que han respondido 91 personas (son 100 en clase). Lo acogen bien.

El día 19 de octubre imparto el tema teórico que estaba previsto. Un tema corto y fácil; todos disfrutamos de los ejemplos clínicos. Les aviso que ese día abro el cuestionario interno del ciclo. Esa misma noche activo el cuestionario interno del ciclo para que me hagan comentarios y preguntas.

El 20 de octubre impartimos el tema de la trombosis y la embolia. En cursos previos se quedan muy extrañados cuando les explico el mecanismo de la embolia paradójica y no es para menos porque es una cosa compleja de entender. Por esa razón, la tarde anterior les pongo en el chat de MsTeams una historia clínica de embolismo paradójico (sin darles la solución) para ver si son capaces de deducirlo ellos mismos. Unos pocos lo hacen, y lo explican por el chat a los demás, que llegan a clase el día 20 de octubre conociendo algo en lo que los alumnos de cursos previos se atascaban en clase. ¡Flipped learning!!

El 21 de octubre abordamos el tema del infarto, y la clase, la adapto completamente a las preguntas que han hecho en tarde anterior a través del chat. Noto que tenemos buena conexión.

Al valorar los cuestionarios posteriores al CIMA B (que responden 88 personas) noto que tienen mucha inquietud por aprender más, y también una marcada satisfacción por el ciclo recién terminado.

\section{Evaluación mediante escalera de aprendizaje}

Los cuestionarios de contenidos tenían 5 preguntas. He construido escaleras correspondientes a las 5 preguntas según la metodología descrita en las referencias 
bibliográficas de esta comunicación (Porlán R, 2017). Sin embargo, por razones de espacio, voy a mostrar la que considero más representativa por el notable progreso en el aprendizaje.

¿Qué morfología pueden tener las lesiones derivadas de las tres alteraciones hemodinámicas?

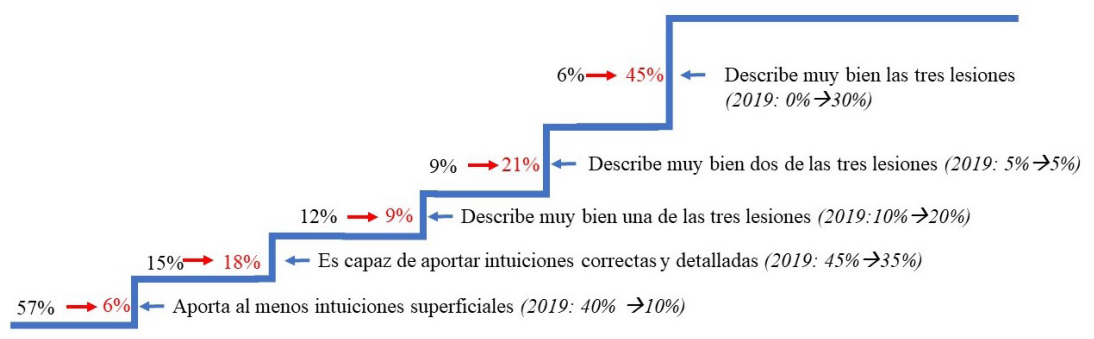

Figura 5. Escalera de aprendizaje de la pregunta no5 del CIMA B. Se comparan los resultados con los del curso pasado (entre paréntesis y en itálica)

En la respuesta a esta pregunta se observa un adecuado avance en el aprendizaje de cuáles son las lesiones asociadas a la trombosis, hemorragia y embolia. Aunque muchos alumnos tenían intuiciones más o menos precisas acerca de dichas lesiones, aproximadamente el $45 \%$ de ellos fueron capaces al final del ciclo de realizar una descripción satisfactoria de las lesiones. Como conclusión para la pregunta estructurante 5 del CIMA B, creo que las innovaciones de este curso han resultado en un mejor aprendizaje que en el curso anterior.

\section{CIMA D}

\section{Resumen del diario de clase}

Comienzo el ciclo el 6 de noviembre de una manera novedosa para ellos (y para mi). Construyo un seminario con imágenes de neoplasias, algunas claramente benignas y otras claramente malignas. Me limito a decirles maligno/

Ciclos de Mejora en el Aula (2020). Experiencias de Innovación Docente de la US Esta obra se distribuye con la licencia Creative Commons 
benigno tras cada imagen (mediante Kahoot) y así les insto a entender de manera inductiva cuáles son las características de una neoplasia maligna y una benigna. Resulta ser un seminario muy práctico sobre nomenclatura tumoral, donde preparamos entre todos una clasificación de las neoplasias 'for dummies'. Contra lo que tenía previsto, me centro en que comprendan que la palabra pólipo es muy ambigua, y que no necesariamente refleja una naturaleza neoplásica. Al finalizar la clase les proporciono una tabla con los criterios de malignidad/benignidad de las neoplasias para que comprueben su aprendizaje.

Continuamos el 9 de noviembre haciéndoles feedback acerca de lo que habían escrito en el cuestionario previo al CIMA D (87 personas han escrito el cuestionario previo). En particular en lo que tiene que ver con la definición de neoplasia. Para ello les construyo y subo a EV una nube de letras formada a partir de sus respuestas a la pregunta no 1 “Qué es una neoplasia?". Esta no era una actividad prevista, pero se me ocurrió unos días antes y creo que sirvió muy bien para que vieran cuáles eran sus concepciones previas al CIMA. Nos quedamos casi toda la clase con este aspecto. Este año conservamos el material del CIMA integrado con Histología (Prof. Fernández Santos) pero no vi práctico que se desplazase a nuestra aula. Les dejo un pequeño problema/mini caso clínico relacionado con la segunda clase. Incluyo preguntas concretas en el chat de MsTeams para que me vayan dando feedback entre clase y clase.

El 10 de noviembre comenzamos abordando el mini-caso clínico propuesto al final de la clase anterior, y nos quedamos un rato largo debatiéndolo. Los contenidos de la clase, relacionados con la diseminación de las neoplasias son extensos, y eso que los he recortado respecto al curso anterior (79 diapositivas respecto a 140), pero aun así dejo algunas para el comienzo de la clase siguiente. Muy 
buen clima de participación en clase, pero pocas preguntas en el cuestionario.

El 11 de noviembre revisamos en clase las bases genéticas de las neoplasias. Noto que les cuesta entender el modelo de Knudson relacionado con el retinoblastoma y los genes supresores tumorales, y me propongo inventar algo al respecto para el próximo curso. Subo a EV un artículo que se publicó en Nature el día anterior sobre las alteraciones genéticas de las metástasis, pero me doy cuenta de que es demasiado complejo para casi todos ellos.

12 de noviembre acabo los contenidos de la clase anterior y abordo un mini caso clínico para centrar el tema de la etiología del cáncer. Todo según lo previsto. Pocas preguntas en el cuestionario.

Termino el ciclo el 16 de noviembre, cerrando todo el CIMA alrededor del diagnóstico de las neoplasias. Es una clase dinámica en la que todos disfrutamos.

Al acabar el ciclo subo a EV mi vídeo con el mapa de contenidos específico del ciclo (en este enlace) (basado en la Figura 3 de este artículo) y los alumnos me reflejan que les ayuda a aprender. Los cuestionarios posteriores al CIMA $\mathrm{D}$ los responden 78 personas.

\section{Evaluación mediante escalera de aprendizaje}

Los cuestionarios de contenidos tenían 5 preguntas. He construido escaleras correspondientes a las 5 preguntas según la metodología descrita en las referencias bibliográficas de esta comunicación (Porlán R, 2017). Sin embargo, por razones de espacio, voy a mostrar la que considero más representativa por la mejoría en el aprendizaje respecto al curso anterior: 
¿Cómo se diseminan las neoplasias?

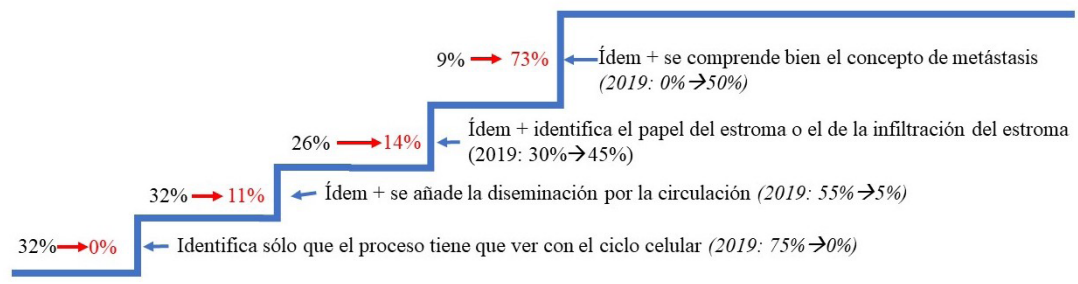

Figura 6. Escalera de aprendizaje de la pregunta no2 del CIMA D

En particular, me llama la atención de que el contenido conceptual de metástasis se ha aprendido de manera mucho más precisa que en el curso pasado, precisamente porque he realizado un mayor hincapié en el mismo durante este curso 2020-2021.

\section{Evaluación de los CIMA. Conclusiones}

Aunque el curso se ha desarrollado sólo en un 55\%, y espero poder enviar otra versión mejorada de esta comunicación a finales de enero, con una evaluación detallada de los objetivos marcados en el apartado "Retos y aspectos a mejorar" se pueden señalar algunos avances conseguidos:

- Hemos sido capaces de centrar la docencia en casos (problemas clínicos reales) y de hecho hemos empezado cada CIMA con casos prácticos. Para no crear inseguridad en los estudiantes, hemos incluido 'clases teóricas' inmediatamente después, para consolidar los conocimientos aprendidos. Así, hemos dedicado a la misma área temática dos formatos diferentes de docencia (clase teórica y seminario, por ejemplo) en dos días correlativos, repartiendo e integrando los contenidos entre los dos tipos de formatos presenciales de

Ciclos de Mejora en el Aula (2020). Experiencias de Innovación Docente de la US Esta obra se distribuye con la licencia Creative Commons 
docencia. El resultado es que la diferencia entre clases teóricas y prácticas/seminarios se ha difuminado notablemente.

- El aprendizaje no sólo no se ha resentido en este curso centrado en herramientas virtuales, sino que, como se muestra en las figuras 6 y 7 , se ha producido un aprendizaje mayor que el conseguido en dos áreas consideradas deficitarias el curso pasado.

- Ha sido fundamental la introducción del chat "proyecto MsTeams 30D" para crear sensación de pertenencia al grupo, aumentar la comunicación de los estudiantes con el profesor, mejorar el aprendizaje colectivo y modular entre una clase y otra los contenidos a impartir.

- Se trata por primera vez de un curso formado por ClMAs virtuales encadenados que cubre completamente el programa de la asignatura.

\section{Aspectos a mejorar:}

- Existen algunas clases cuyos materiales aún son demasiado largos y complejos, y necesitarían ser jerarquizados y resumidos. Me doy cuenta al impartir la clase y los alumnos me los señalan en los cuestionarios postCIMA, donde les pregunto, CIMA a CIMA por su propio aprendizaje

- Convendría escribir pies de figura en algunas figuras con contenidos complejos.

\section{Calificación del curso}

Propongo para este curso la siguiente tabla de calificaciones:

- Examen final: 30\%, centrado de manera mayoritaria en los casos debatidos en los CIMAs

- Evaluación continua: 70\%

- Participación mediante cuestionarios previos/posteriores a cada CIMA (Google Forms y gamificación

Ciclos de Mejora en el Aula (2020). Experiencias de Innovación Docente de la US Esta obra se distribuye con la licencia Creative Commons 
Kahoot). Se valora la frecuencia y la calidad de la participación: $20 \%$

- Pruebas de evaluación continua desarrolladas al final de cada CIMA (módulo examen de BlackBoard Collaborate: $50 \%$ )

Palabras clave: Medicina, Anatomía Patológica, docencia universitaria, experimentación docente universitaria, Clase inversa, Aprendizaje Basado en problemas

Keywords: Medicine, Pathology, University Teaching, University Teaching Experimentation, Flipped Class, Problem Based Learning.

\section{Bibliografía}

Blain, K. (2007). Lo que hacen los mejores profesores de Universidad. Valencia: Publicaciones de la Universitat de Valéncia.

De Alba N y Porlan R (Eds) (2020). Docentes universitarios, una formación centrada en la práctica. Madrid, Ediciones Morata.

Finkel, D. (2008). Dar clase con la boca cerrada. Valencia: Publicaciones de la Universitat de Valéncia.

Prieto Martín A (2018). Flipped learning. Aplicar el modelo de aprendizaje inverso. Madrid. Ediciones Narcea.

Ciclos de Mejora en el Aula (2020). Experiencias de Innovación Docente de la US Esta obra se distribuye con la licencia Creative Commons 